\title{
Prospecção da doença de Chagas NA REGIÃo de JANAÚBA, MINAS GERAIS
}

\author{
JOAO CARLOS PINTO DIAS \\ Centro de Pesquisas René Rachou, Fundação Oswaldo Cruz, C. P. 1743 \\ 30000 Belo Horizonte, MG, Brasil
}

SINOPSE. Relata-se uma atividade prospectiva para doença de Chagas em uma ampla região de projetos de colonização ao norte de Minas Gerais. Pesquisa de triatomíneos e tripanossomos e inquéritos clínico e sorológico na população revelaram presença marcante de triatomíneos na área, com mais de $60 \%$ dos domicílios infestados por Triatoma infestans ou $T$. sordida, com indices globais de positividade para Trypanosoma (Schizotrypanum) cruzi ao nível de $60 \%$ dos insetos capturados. Definem-se duas situaçōes distintas segundo a domiciliação destas espécies, estando a de $T$. infestans seguramente ligada aos padrōes precários de habitação das populações mais pobres, especialmente em Lagedinho e Gado Bravo, com altos índices de densidade domiciliar desta espécie. T. sordida predomina aparentemente ao sul (Janaúba), sugerindo-se que a espécie esteja ainda em fase predominantemente silvestre, com focos esporádicos de domiciliação.

A análise da população revela índices relativamente altos de infecção (globalmente em tomo de $10 \%$ ) demonstrável sorologicamente, indicando-se transmissão recente através de exames positivos em pessoas de baixa idade. A aparente escassez de formas clínicas graves sugere, em princípio, que a doença de Chagas esteja, no momento, se implantando na região como doença humana, reproduzindo ali o que deve ter ocorrido em vastas extensões do paŕs nos últimos 200 anos.

Paralelamente ao interesse do estudo ecológico da interação homem-vetor-tripanossomo, a situação observada parece constituir importante modelo para situações concretas e atuais, como seja a conquista da Amazônia, inclusive e principalmente em relação às medidas de prevenção cabiveis em benefício de populações pioneiras.

A partir de sua condiçāo primitiva como enzootia silvestre, a tripanossomíase americana incorporou-se à nosologia humana de vastas áreas da América Latina após a conquista definitiva dos territórios pelo homem, traduzida pelos processos de colonização que propiciaram o contato de colonizadores com triatomíneos vetores. Segundo Martins (1968), só ocorre endemia humana onde se dá a "domiciliação" dos triatomíneos, o que, por sua vez, parece depender de dois fatores primordiais: primeiramente a reduçāo da fauna silvestre, geralmente devida a desmatamento, forçando os triatomíneos primitivamente silvestres a buscar novas fontes de alimento. Em segundo lugar, a existência de um tipo de habitação humana que ofereça aos insetos vetores condições próprias à sua colonização.

Os trabalhos de colonização que ora se desenvolvem em várias e vastas regiōes do Brasil têm sido preocupação constante de meios científicos e governamentais, a ponto de delinear-se amplo projeto interdisciplinar, recentemente, para a avaliação prospectiva de potencialidades nosológicas das áreas de influência da Rodovia Transamazônica, inclusive da doença de Chagas (Deane, 1973). Da mesma forma, a implantação de uma política de aproveitamento racional e planificado se desenvolve em áreas extensas do norte de Minas Gerais, em especial as situadas na região mineira do Polígono das Secas, preocupando as autoridades no tocante às condiçōes de saúde das populações primitivas e pioneiras (Fundação João Pinheiro, 1975). Dados antigos têm caracterizado a presença marcante da

Trabalho patrocinado pela Fundação Laura de Andrade, Belo Horizonte.

Recebido em 27 de outubro de 1975. 
doença de Chagas em Minas Gerais e nesta própria região, tanto em relação à prevalência da infecçāo humana (Fundaçāo SESP, 1968; Salgado \& Pellegrino, 1968) quanto à infes taçāo domiciliar por triatomíneos (SUCAM, 1975) e à presença de formas clínicas graves traduzidas por altos coeficientes de mortalidade e demanda à atenção médica (Maurício, 1959). As novas áreas de colonização desta região a partir de 1971 têm atraído e fixado populações à custa de projetos especiais, ligados à implantação racional de uma pecuária $\mathrm{e}$ uma agricultura adequadas às condiçōes existentes e ao desenvolvimento posterior de projetos industriais correlatos. Estas atividades têm implicado desmatamento extensivo. Quais as perspectivas da doença de Chagas para tais áreas?

Ligada diretamente a quatro projetos agropecuários na região, a Fundaçāo Laura de Andrade, através de sua Diretoria, foi despertada pelo achado constante de triatomíneos nos respectivos núcleos. Originou-se assim um trabalho de prospeç̧ão na área, por uma equipe da Fundação Oswaldo Cruz, resultando a presente nota.

Objetivou-se, a partir de informações gerais da área, questionar a existência dos fatores integrantes do ciclo da endemia e levantar indicadores sobre a incidência, a prevalência e o potencial de morbidade na população humana, definindo-se finalmente uma política de atenção ao problema.

\section{DESCRIÇÃO SUMÁRIA DAS ÁREAS ESTUDADAS}

Foram percoridas regiões dos municípios de Janaúba, Monte Azul e Manga, situados ao norte de Montes Claros (Mapa), mais particularmente relacionadas às depressões por onde correm os rios Gorutuba e Verde Grande. Trata-se de área seca e transicional, com altitudes variando de 500 a $600 \mathrm{~m}$, em que as matas secas exprimem a mudança ecológica para o domínio da caatinga, estando relacionadas à presença de solos oriundos de decomposiçāo de calcários existentes nas citadas depressões (Fundaçāo João Pinheiro, 1975). O clima é quente e homogêneo, com pluviosidade concentrada de outubro a março (totais de 900 a $1.100 \mathrm{~mm}$ ). À época desta pesquisa (julho de 1975), a temperatura diária foi de $240 \mathrm{C}$. A região apresentava-se intensamente seca, com suas árvores totalmente desfolhadas (Caatinga Arbórea).

A população é caracteristicamente iovem. mais de 55\% abaixo dos 20 anos de idade, basicamente rural $(72,1 \%)$, com densidade muito baixa $\left(8 \mathrm{hab} / \mathrm{km}^{2}\right.$ contra 19,6 $\mathrm{hab} / \mathrm{km}^{2}$ do Estado de Minas Gerais para 1970: Fundaçāo SESP, 1968). Observam-se correntes migratórias regionais, oriundas de êxodo rural e de fluxo para os pólos de implantacão industrial (Montes Claros, Pirapora) e grandes projetos agropecuários (Fundação João Pinheiro, 1975; IPPEDASAR, 1972).

\section{METODOLOGIA}

Para a pesquisa de triatomíneos e tripanossomos utilizou-se a metodologia tradicional de busca intra e peridomiciliar, com aplicação de insetífugo (piretrinas). Os triatomíneos capturados e catalogados foram a exame no laboratório do Posto Dr. Emmanuel Dias, Bambuí, através de dissecção do digestivo terminal.

Para a pesquisa de focos silvestres, foi aplicado o insetífugo nos ocos de árvores, sendo também derrubados alguns exemplares que abrigavam morcegos, cujos caules (ocos) eram abertos longitudinalmente para a pesquisa.

$O$ exame da população humana foi realizado através da coleta de sangue em 5 localidades: a) Fazenda Colonial e pessoal dos arredores (município de Janaúbả); b) Povoado de Novo Horizonte e núcleo Rio Verde (municípios de Monte Azul e Manga); c) Povoado de Gado Bravo (município de Manga); d) Povoado de Lagedinho (município de Manga); e) Fazenda Lagoa Verde (município de Manga).

Fez-se a coleta de sangue através da técnica de Salgado \& Pellegrino (1957) para punção venosa em antebraço. Usou-se ainda a coleta em ponta de dedo para recepção em 
papel de filtro destinado à hemaglutinação (Batista, 1973).

As reaçōes sorológicas foram através da técnica de fixação do complemento (50\% da hemólise, antígeno metílico), sendo alguns soros testados em cego pela RHA e TIF. As reações de hemaglutinação em papel filtro foram processadas no Serviço do Prof. Sebastiáo M. Batista (Instituto de Ciências Biológicas, Universidade Federal de Minas Gerais).

Paralelamente foram feitas entrevistas médicas e exames clínicos sumários em parte da população submetida à coleta de sangue, objetivando detectar fatos ou informaçōes acerca de manifestações clínicas da doença de Chagas.

Técnicos sociais (uma educadora sanitária e uma assistente social) completaram o trabalho, efetuando entrevistas acerca dos conhecimentos e capacidades da população frente à doença de Chagas, bem como analisando o contexto geral da vida desta população, em especial quanto aos aspectos de habitação e alimentação.

Os soros colhidos foram conservados em geladeira, posteriormente transportados em isopor com gelo picado, de avião, para Belo Horizonte, seguindo no mesmo dia para Bambui.

O trabalho desenvolveu-se durante 4 dias da primeira semana de julho de 1975. Nāo houve, aparentemente, seleção alguma das pessoas para a sorologia, colhendo-se, em geral, o sangue de todos os presentes no momento, na localidade visitada. Paralelamente à coleta e exames, tem sido eficaz a prática da administração de um comprimido ascaricida (Tetramizole) a cada paciente, o que de certa forma lhe confere algum benefício e propicia melhor aceitação do técnico e do exame.

\section{RESULTADOS}

\section{SOROLOGIA}

Foram colhidas, ao todo, 462 amostras de sangue na região, tendo sido aproveitadas $445(96,4 \%)$. Destas, 144 o foram em papel de filtro $(32,4 \%)$ e as demais por punção venosa. As 17 não aproveitadas constituíram-se de material insuficiente, quebra de frasco e resultados inconclusivos (anticomplementares).

As Tabelas 1 a 9 resumem os resultados. Houve um total de 47 exames positivos dentre o total de 445 examinados e conclusivos, condicionando $10,6 \%$ de positividade sorológica para a população em geral.

$\mathrm{O}$ estudo comparativo entre as sub-regiōes, cotejando-se a positividade global de cada uma (Tabelas $3,6,7$ e 8 ) revelou a inexistência de diferenças estatisticamente significativas entre as taxas encontradas, pelo teste de $\chi^{2}, \operatorname{com} p$ ao nível de 0,01 .

De modo geral, houve tendência à diferença entre as positividades reacionais para os grupos etários abaixo e acima de 15 anos de idade (Tabela 9), com maiores taxas nos indivíduos mais velhos. Esta diferença foi francamente significativa para a Fazenda Colonial (Tabela $3, \chi^{2}$ de 6.61 , altamente significativo) mas não apresentou significação estatística para o conjunto Lagedinho/Gado Bravo $\left(\chi^{2}\right.$ de 0,1 - Tabela 7$)$, nem para o de Novo Horizonte/Rio Verde (Tabela 4).

\section{LEVANTAMENTO TRIATOMINICO-TRIPANOSSOMICO}

Foram capturados 216 exemplares de triatomíneos, sendo $25 T$. sordida, $191 \mathrm{~T}$. infestans e $1 P$. diasi (Tabelas 10 e 11 ). Os focos foram basicamente domiciliares, constando de 15 casas positivas, uma dependência de curral e 2 árvores ocas. Ao que tudo indica, predomina amplamente o $T$. infestans mais ao norte (Lagedinho, Gado Bravo e Fazenda Lagoa Verde), encontrando-se igualmente as duas espécies principais na área de Janaúba, mais ao sul. Na área de Novo Horizonte, intermédia, foram encontradas ambas as espécies, com aparente predomínio do $T$. infestans. Aliás, nesta última área a densidade triatomínica foi bem mais baixa, em termos de percentuais de domicŕlios infestados ou dos índi- 

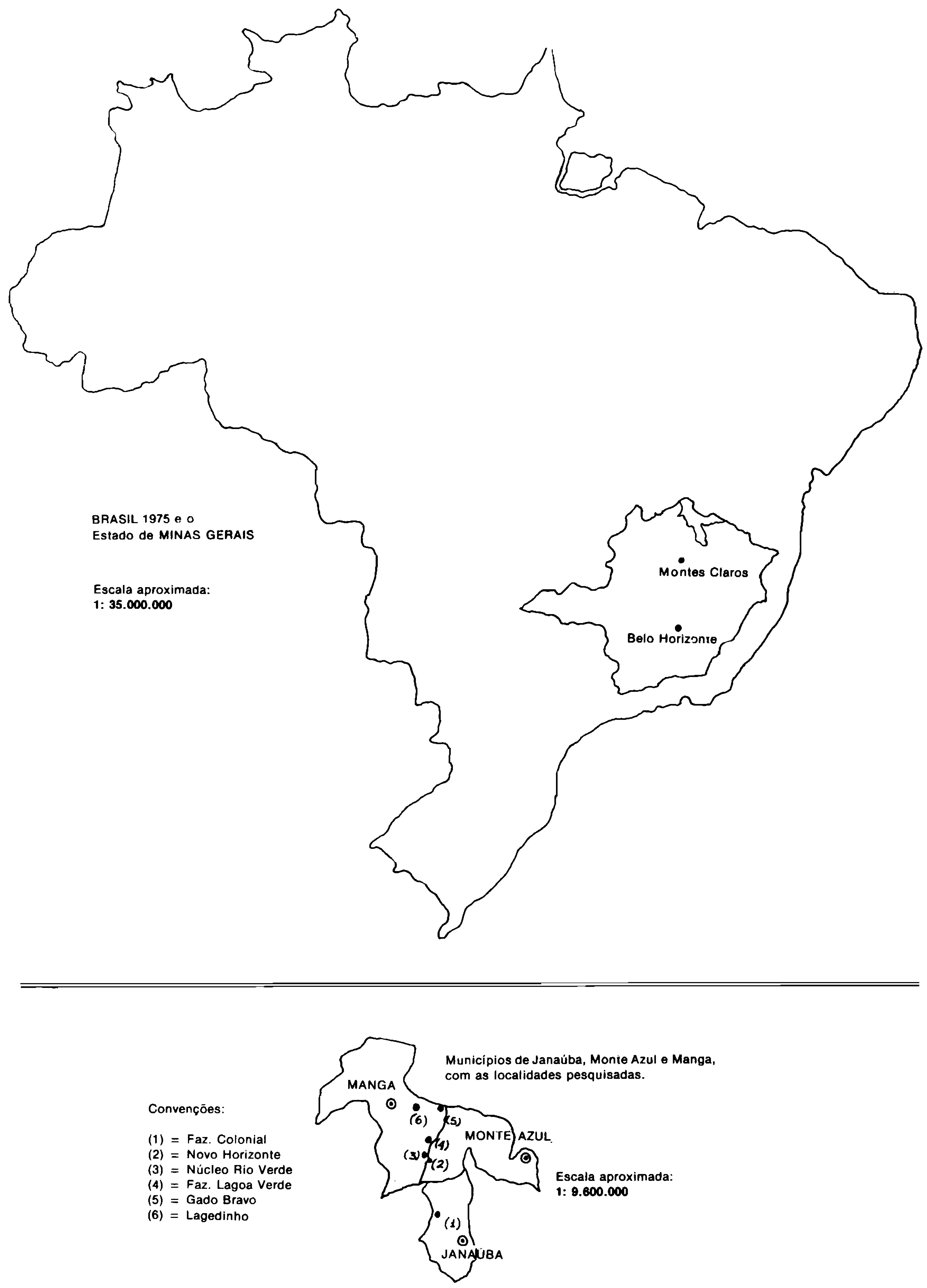
ces de captura por casa positiva (observações de 30 minutos). Isto se explica, provavelmente, pela característica semi-urbana desta população, bem como pela situação mais descampada da área, com casas bem mais afastadas da mata, que nas duas outras.

$\mathrm{Na}$ região da Fazenda Colonial (Mun. Janaúba), das 6 casas comprovadamente positivas, 4 estavam infestadas pelo $T$. sordida, uma das quais com estádios jovens, indicando domiciliação. As duas restantes apresentaram $T$. infestans, uma das quais com formas jovens. Não houve casos de infestação mista. Nesta Fazenda, a maioria dos empregados efetivos reside em casas boas, de alvenaria, sendo nestas encontrado o $T$. sordida (inclusive na sede). O $T$. infestans foi capturado em casas de padrão social bem inferior, construídas de tábuas e cobertas de palha ou telhas. Na maioria das capturas de T. sordicla o número de insetos foi muito baixo, geralmente um ou dois adultos, sem indícios de colonização, como fezes e/ou exúvias. Os moradores reconhecem perfeitamente as 2 espécies referidas. afirmando unânimes que uma delas (T.sordida) vem da mata, voando, à noite. Na própria casa em que a equipe se instalou, de moderna alvenaria, foi capturado 1 exemplar adulto desta espécie, na parede de um quarto logo na manhã do 20 dia, sem nenhum vestígio de colonização, tendo a casa sido limpa na tarde anterior.

Estes fatos, mais as informações prévias dos proprietários da fazenda, levaram a uma pesquisa de focos silvestres, tendo o $T$. sordida sido facilmente encontrado no caule oco de árvores à volta das casas, em todos os estádios evolutivos. Tais árvores -. "Ipê" (Tabebuia sp.), "Peroba" (Aspidosperma peroba) e outras - abrigam um sem número de roedores, pequenos lagartos, rās arborícolas e morcegos, que provavelmente alimentam os triatomíneos. Há muito poucos galinheiros em todas as áreas percorridas; o único foco peridoméstico encontrado, foi em um curral de bezerros novos, para $T$. sordida em fase de procriação (ninfas e ovos).

$\mathrm{Na}$ região intermediária a populaçāo é muito recente, havendo um núcleo de co. lonização programada (Ruralminas, entidade colonizadora) e umı povoado muito pobre $\mathrm{e}$ desprogramado, com alta densidade populacional, Novo Horizonte. Foram encontrados 2 focos de colonização de $T$. infestans em domicílio (N. Horizonte) e 1 exemplar adulto de $T$. sordida em alojamento próximo ao Hotel (Rio Verde). Recebeu-se ainda 1 exemplar adulto (morto) de $P$. diasi encontrado por morador (Rio Verde).

A regiâo mais ao norte, já nos confrontos com a Bahia, é extremamente pobre, com graves problemas de abastecimento de água, vivendo a população às margens do Rio Verde Grande (como Gado Bravo) ou em pequenos núcleos à volta de poços artesianos construídos pela Ruralminas (como Lagedinho). Nestas populaçōes há franca referência à presença de "chupões" dentro de casa, o que se pôde constatar com extrema facilidade. As informaçōes são explícitas, para a presença de tais insetos em toda a área. Só foram en. contrados $T$. infestans. Em Lagedinho, após a terceira casa pesquisada e abundantemente infestada (como as 2 anteriores), percebeu-se que a localidade seria toda no mesmo padrão. Sem maiores preocupações numéricas, centenas de formas evolutivas de $T$. infestans foram desalojadas pela Pirisa, em poucos minutos, fato repetido nas demais casas.

Entre Rio Verde e Gado Bravo, uma série de glebas em fase inicial de colonização (desmatamento, plantio de capim). População discreta, nesta fase. Visitada, a Fazenda Lagoa Verde revelou 2 focos domiciliares de $T$. infestans, com colonização desta espécie em baixa densidade.

As taxas de infecção dos triatomíneos capturados por $T$. (S.) cruzi, podem ser vistas na Tabela 11 . O coeficiente global de $6,0 \%$ é semclhante aos 7,3\% encontrados pela SUCAM para a região de Montes Claros (Fundação SESP, 1968). O tratamento estatístico não revelou diferença significativa entre a positividade global das espécies $\left(\chi^{2}=0,20\right)$. Chamou atenção, todavia, a possibilidade relativa alta das formas jovens de $T$. sordida, à custa de uma captura em domicílio. 
Tabela I

Sorologia para doença de Chagas pela RFC* na populaçāo da Fazenda Colonial c cercanias, Janaúbx, MG, julho de 1975.

\begin{tabular}{l|c|c|c}
\hline Result. & $1-15$ & $16 \mathrm{e}+$ & Total \\
\hline+ & 9 & 8 & 17 \\
\hline- & 71 & 33 & 104 \\
\hline S. total & 80 & 41 & 121 \\
\hline$\%+$ & 10,5 & 19,5 & 14,0 \\
\hline
\end{tabular}

* $10 \%$ das reações comprovadas por TIF

\section{Tabela II}

Sorologia para doença de Chagas pela RHA (em papel de filtro) na população da Fazenda Colonial c cercanias, Janaúba, MG, julho de 1975.

\begin{tabular}{l|c|c|c}
\hline Idades & 1 & $16 \mathrm{e}+$ & Total \\
\hline+ & 1 & 3 & 4 \\
\hline- & 33 & 8 & 41 \\
\hline S. total & 34 & 11 & 45 \\
\hline$\%+$ & 2,9 & 27,3 & 8,9 \\
\hline
\end{tabular}

\section{Tabela III}

Sorologia para doença de Chagas na Fazenda Colonial e cercanias, Janaúba, MG, julho de 1975. Resultados englobados (RFC + RHA)

\begin{tabular}{l|c|c|c}
\hline Idades & $1-15$ & $16 \mathrm{e}+$ & Total \\
\hline+ & 10 & 11 & 21 \\
\hline- & 104 & 41 & 145 \\
\hline S. total & 114 & 52 & 166 \\
\hline$\%+$ & 8,8 & 21,2 & 14,5 \\
\hline
\end{tabular}




\section{Tabela IV}

Sorologia para docnça de Chagas pela $\mathrm{RFC}^{*}$ na população geral de Novo Horizonte e Jaıba, Munic de Montc Azul, MG, julho de 1975.

\begin{tabular}{c|c|c|c}
\hline Idades & $1-15$ & $16 \mathrm{e}+$ & Total \\
\hline+ & 9 & 3 & 12 \\
\hline- & 96 & 30 & 126 \\
\hline S. Total & 105 & 33 & 138 \\
\hline$\%+$ & 8,6 & 9,0 & 8,7 \\
\hline
\end{tabular}

$*=15 \%$ comprovadas por TIF.

\section{Tabela V}

Sorologia para doença de Chagas pela RHA (em papel de filtro), na populaçāo geral de Novo Horizonte e Jaíba, Município de Monte Azul, MG. julho de 1975. (Apenas menores de 3 anos de idade).

\begin{tabular}{c|c|c|c}
\hline Idade & $1-15$ & $16 \mathrm{e}+$ & Total \\
\hline+ & 0 & 0 & 0 \\
\hline- & 17 & 0 & 17 \\
\hline S. Total & 17 & 0 & 17 \\
\hline$\%+$ & 0 & 0 & 0 \\
\hline
\end{tabular}

\section{Tabela VI}

Sorologia para docnça de Chagas na população geral de Novo Horizonte e Jaíba, Município de Monte Azul, MG, jutho de 1975. Resultados englobados (RFC + RHA).

\begin{tabular}{c|c|c|c}
\hline Idades & $1-15$ & $16 \mathrm{e}+$ & Total \\
\hline+ & 9 & 3 & 12 \\
\hline- & 113 & 30 & 143 \\
\hline S. total & 122 & 33 & 155 \\
\hline$\%+$ & 7,4 & 9,0 & 7,7 \\
\hline
\end{tabular}




\section{Tabela VII}

Sorologiz para doença de Chagas pcla RHA (cm papel de filtro) na população geral de Gado Bravo e Lagedinho. Municipios de Manga e Monte Azul, MG, julho de 1975.

\begin{tabular}{c|c|c|c}
\hline Rcult. & $1-15$ & $16 \mathrm{e}+$ & Total \\
\hline+ & 5 & 3 & 8 \\
\hline S. total & 50 & 24 & 74 \\
\hline$\%+$ & 55 & 27 & 82 \\
\hline
\end{tabular}

Tabela VIII

Sorologia para doença de Chagas pela RFC: na populaçāo da Fazenda Lagoa Verde, Município de Manga, MG, julho de 1975.

\begin{tabular}{l|c|c|c}
\hline Idider & $1-15$ & $16 \mathrm{c}+$ & Total \\
\hline+ & 0 & 6 & 6 \\
\hline S.cialt. total & 2 & 34 & 36 \\
\hline$\%+$ & 2 & 40 & 42 \\
\hline
\end{tabular}

* $15 \%$ comprovador pela Tll:

\section{Tabela IX}

Resultados gerain conglobador (soma de técnicas* c localidades) da pesquisa sorológica para doença de Chagas em uma área do norte de Minas Gerais, julho de 1975.

\begin{tabular}{c|c|c|c}
\hline Rdiades & 115 & $16 \mathrm{c}+$ & Totais \\
\hline+ & 24 & 23 & 47 \\
\hline- & 269 & 129 & 398 \\
\hline S. total & 293 & 152 & 445 \\
\hline$\%+$ & 8.2 & 17,8 & 10,6 \\
\hline
\end{tabular}

* = RITC ERHA 
Tabela X

Infestação domiciliar (e peridomiciliar) por triatomíneos $\mathrm{cm}$ localidades rurais do norte de Mina Gerais, julho de 1975.

\begin{tabular}{|c|c|c|c|}
\hline Localidade & $\begin{array}{c}\text { Casas } \\
\text { Pesquisadas }\end{array}$ & $\begin{array}{c}\text { Casas com } \\
\text { triatomíneos }\end{array}$ & $\begin{array}{l}\text { \% casas com } \\
\text { triatomineos }\end{array}$ \\
\hline $\begin{array}{l}\text { Faz. Colonial } \\
\text { (Mun. Janaúba) }\end{array}$ & 9 & $\begin{array}{ll}6 \quad(1) \\
& (2)\end{array}$ & 66.7 \\
\hline $\begin{array}{l}\text { N. Horizonte } \\
\text { e N. Jaíba } \\
\text { (Mun. M. Azul) }\end{array}$ & 7 & $\begin{array}{ll}3 & (2) \\
& (3)\end{array}$ & 42.9 \\
\hline \multirow{2}{*}{$\begin{array}{l}\text { Gado Bravo } \\
\text { Ladeginho e } \\
\text { Lagoa Verde } \\
\text { (Mun. Manga) }\end{array}$} & 7 & $6 \quad(2)$ & 85.7 \\
\hline & 23 & 15 & 65,2 \\
\hline
\end{tabular}

* - ou com indícios recentes (fczes, exúvias)

(1) - T. sordida

(2) $-T$. infestans

(3) - P. diasi (apenas 1 exemplar, adulto)

\section{Tabela XI}

Fases evolutivas e infeção por $T$. (S.) cruzi das principais espécies de triatomíneos capturados no norte de Minas Gerais, julho de 1975.

\begin{tabular}{|c|c|c|c|c|c|c|c|c|c|}
\hline \multirow{2}{*}{$\begin{array}{r}\begin{array}{r}\text { Espécie e } \\
\text { positivi- } \\
\text { dade }\end{array} \\
\text { Estágio }\end{array}$} & \multicolumn{3}{|c|}{ T. infestans } & \multicolumn{3}{|c|}{ T. sordida } & \multicolumn{3}{|c|}{ Totais } \\
\hline & Capt. & + & $\%+$ & Capt. & + & $\%+$ & Capt. & + & $\%+$ \\
\hline Adultos & 52 & 4 & 7,7 & 9 & 0 & 0,0 & 61 & 4 & 6,6 \\
\hline Larvas & 139 & 7 & 5,0 & 16 & 2 & 12,5 & 155 & 9 & 5,8 \\
\hline Totais & 191 & 11 & 5,8 & 25 & 2 & 8,0 & 216 & 13 & 6,0 \\
\hline
\end{tabular}




\section{AVALIAÇÃO CLINICA SUMÁRIA}

Através. especialmente, de uma anamnese semidirigida e da ausculta cardíaca de pessoas adultas jovens, aproximadamente $20 \mathrm{em}$ cada área visitada. Nāo foram encontrados sinais de arritmias ou insuficiência cardíaca, mesmo entre aqueles cuja sorologia veio, posteriormente, revelar-se positiva. Não se ouviu, na área, referências a distúrbios do esôtago. Há citações vagas e esparsas acerca de prisẫo de ventre em pessoas adultas. Há poucas referências, isoladas, sobre pessoas falecidas repentinamente ou edemaciadas, embora se saiba da grande prevalência de cardiopatia chagásica em regiôes mais próximas a Montes Claros (IPPEDASAR, 1972; Maurício, 1959).

\section{ATIVIDADES DE CONTROLE ENCONTRADAS NA ÁREA}

Nas Fazendas Colonial e Lagoa Verde há preocupação com os triatomíneos, além de um certo nível de consciência acerca da doença. A população menos estável, entretanto, nestas mesmas fazendas, é bastante primitiva, o que se reflete na grande precariedade da habitação. Há aplicação de inseticidas pela população mais diferenciada, mormente o "Folydol" (suspensão), além do DDT pela CEM.

Em Novo Horizonte há pouca preocupação com os triatomíneos, embora alguns moradores façam aplicar, esporadicamente, o "Folydol".

Para as regiões de Lagedinho e Gado Bravo, áreas de maiores índices de infestação, embora os triatomíneos incomodem à noite e parte da população tenha certo grau de consciência acerca da doença, a problemática mais à tona é outra. Trata-se, principalmente, de abastecimento de água, de regularização de posse às pequenas glebas e do asseguramento de um emprego ou de qualquer outra forma de sobrevivência econômica. Alguns moradores contratam eventualmente os serviços de um desinsetizador particular ambulante, que cobra $\operatorname{Cr} \$ 8,00$ a $\operatorname{Cr} \$ 10,00$ "por cômodo" pela aplicação de "Folydol". Praticamente não há atividade organizada, aqui, de melhoria de habitação, salvo raríssimas exceções.

O "Folydol" é, portanto, o inseticida universal. Trata-se de uma suspensão em querosene de 7,5\% de parathion e 30\% de DDT, da casa Bayer. O parathion, composto ativo, é um fosforado de toxicidade alta e destituido de poder residual, o que explica sua aparente ineficácia numa área com alto potencial de reinfestação das casas.

Não há referência nem indícios de presença recente da SUCAM nas últimas regiōes referidas (Gado Bravo e Lagedinho).

\section{DISCUSSÃO E SUGESTÕES}

A presente investigaçāo se justificou plenamente, através do potencial concreto que representa a doença de Chagas nas regiōes visitadas. Dentre as demais preocupaçōes, é extremamente justa e oportuna também aquela que objetiva dimensionar e prevenir, se for o caso, uma enfermidade de evolução lenta, capaz de lesar gravemente ou mesmo matar considerável percentagem dos indivíduos infectados, justamente na época mais produtiva de suas vidas. É extremamente louvável que tal preocupação parta espontaneamente de entidades de natureza não governamental, dividindo efetivamente com o Poder Público tarefas de alta responsabilidade.

Os resultados encontrados permitem delimitar-se duas situações distintas, segundo a ecologia humana e os aspectos mais diretamente ligados ao vetor. Mais ao norte, uma área primitiva, com precaríssimas condições sócio-culturais da população, altos níveis de infestação domiciliar por $T$. infestans. Prevalência alta da infecção chagásica humana, sugerindo-se ocorrência atual de transmissão através dos índices sorológicos elevados entre crianças de baixa idade. Paradoxalmente, poucas informações ou evidências de formas clfnicas graves entre os adultos, o que poderia significar apenas um problema de transmissão 
recente com pouco tempo, ainda, de evolução, ou uma tendência regional à infecção mais benigna. $\mathrm{O}$ alto potencial de transmissão, definido pelas condições precárias da habitação e pelas altas taxas de infestação domiciliar por $T$. infestans, caracteriza a área como de grande risco para doença de Chagas, sugerindo atenção incisiva e imeđiata, em nivvel governamental. A população não apresenta condições, no momento, para se organizar a respeito. Sugere-se o envolvimento da "Ruralminas", órgão estatal promotor de várias intervenções na área, em conexão com a SUCAM e a Secretaria de Estado da Saúde, esta através de seu Centro Executivo Regional em Montes Claros. Urge a reavaliação mais profunda da situação delineada, apressando-se, ao menos, cobertura da área com BHC, em primeira instância.

Ao sul, nas glebas próximas a Janaúba, duas subdivisões da situação:

a) População mais estável, casas melhores, invasão domiciliar esporádica por $T$. sordida proveniente da mata próxima: potenciais de domiciliação e transmissão mínimos ou discretos.

b) População marginal, indiferenciada, casas precárias, evidências de domiciliação de $T$. infestans: potencial de transmissão alto.

Para a população estável, moradora nas casas de alvenaria, a conduta deve supor a potencialidade remota de domiciliação do $T$. sordida, não justificando a aplicação intensiva de inseticida intradomiciliar para finalidade antitriatomínica. Convém, sim, intensificação das medidas de limpeza normais, para dificultar que formas adultas vindas dos biótopos silvestres permaneçam dentro das casas, especialmente fêmeas fecundadas que poderiam principiar uma colônia em condições mínimas de abrigo. Paralelamente seria conveniente o saneamento específico do peridomicílio através de:

19 - Higiene de possíveis criadouros "artificiais", especialmente galinheiros (aliás raros em toda a região), através de limpeza habitual e/ou desinsetização com BHC a $30 \%$ com 2 expurgos anuais intervalados de 2 ou 3 meses; mesma conduta para depósitos peridomésticos de lenha, madeira, telhas ou tijolos;

2 ? - Ação específica sobre os criadouros silvestres representados pelas árvores ocas: num raio de 50 metros a partir de cada residência, poderiam ser tratadas todas essas árvores, através da fumigação de BHC dentro dos ocos ou da aplicação de suspensão aquosa do pó a $30 \%$, com bombas de pressão, também na periodicidade supracitada para os primeiros 2 ou 3 anos. Outra alternativa seria a introdução de placas de liberaçāo lenta de DVP (tipo "Vapona" - Shell) no interior dos caules, em períodos de 7 a 10 dias, na área em questão;

39 - Ação mais radical, em instância posterior, através da eliminação de tais árvores dentro do perímetro supradefunido.

O raio de 50 metros foi estimado em função do raio de vôo dos triatomíneos (Barretto, 1968) e a periodicidade da aplicação de BHC nos tratalhos de profilaxia embasados em dados do ciclo evolutivo dos triatomíneos (Dias, 1958).

Para a população que habita as casas não de alvenaria, a tarefa base será a reforma ou substituição das mesmas, ou, pelo menos, a aplicação sistemática de BHC nos 2 primeiros anos, seguida de esquema de vigilância. Sugere-se a nivel local a montagem de uma organização simples após esta "fase de ataque", objetivando-se barateamento de custo: criação de uma unidade central de notificação de focos (a Escola ou a Administração da Fazenda, por exemplo) onde seriam recebidos exempiares capturados de triatomíneos. $\mathrm{O}$ 
responsável, confirmada a notificação, faria expurgar imediatamente aquele foco através de pessoa devidamente capacitada, com bomba apropriada e inseticida de ação residual (BHC). Tal esquema vem sendo utilizado com eficiência bastante aceitável na consolidação da vigilància antj-Chagas no Município de Bambuí, MG (Dias \&Garcia, 1975).

Para as regiões com situação intermediária sugere-se: em Jaíba e Novo Horizonte, a partir especialmente da Ruralminas, entendimentos diretos com a SUCAM para reavaliação mais ampla da situação e programação específica decorrente da mesma. Possivelmente scria viável a implantaçāo de um esquema de vigilância como o supracitado, após uma atividade inicial prospectivo-executiva denominada "expurgo-seletivo" (Freitas, 1968), esquema que aparentemente tem dado bons resultados em áreas de transição e com baixas densidades domiciliares de triatomíneos.

Para as glebas organizadas ao norte (Fazenda Lagoa Verde), dentro do possível, realizar a locação e construção de casas segundo o explanado para a "Colonial".

\section{ABSTRACT}

\section{A. prospect of Chagas' disease in the area of Janaúba, Minas Gerais}

A prospective activity on Chagas' disease is reported in a wide region of colonization projects at the northern part of Minas Gerais. Triatomine-trypanosome search and sorological clinical inquiry among the population revealed a marked presence of triatoms in the area, with more than $60 \%$ of the dwellings infested by $T$. infestans or $T$. sordida, with global indexes of positiveness to $T$. (S.) cruzi at the level of $6.0 \%$ of the captured bugs. Two distinct situations are defined according to the dwelling place of these species, T. infestans being undoubtedly associated to the precarious patterns of the poorer population's dwallings, especially in Lagedinho and Gado Bravo, with high indexes of domicilc density of this species. $T$. sordida apparently prevails on the southern part of Janaúba, and we may suggest that the species is still in the predominant wild nhase, with sporadic domiciliated foci.

The analysis of the population reveals relative high indexes of infection (about $10 \%$ ), sorologically demonstrated, showing recent transmission through positive examinations in low-aged persons. The apparent scarcity of serious clinical forms suggests at first that Chagas disease is, at the moment, being implanted as a human disease and is reproducing there, which must have occurred in a large extension of the nation, for the past two hundred years.

Parallel to the ecological study of the interaction man-vector-trypanosome, the detected situation seems to constitute an important model for concrete and actual situations, as the conquest of Amazonia inclusive and specially in relation to the measures taken regarding the convenient prevention in benefit of the pioneer populations.

À Fundação Laura de Andrade, pelo patrocínio desta pesquisa, inclusive através de transporte aéreo e todas as facilidades na área.

Aos Drs. Sebastião M. Batista e Clea Chiari, do Departamento de Parasitologia do Instituto de Ciências Biológicas da UFMG, pelo cotejamento da sorologia.

Ao Prof. Mário E. Camargo, do Instituto de Medicina Tropical de São Paulo, pela gentileza na cessão de antígenos.

A Angelina Garcia, Alice Montandon, Rosinha Borges Dias, José Cândido da Silva e Alexandrino Batista Fernandes. membros da equipe de trabalho, pela grande colaboração. 


\section{REFERENCIAS}

BARRETTO, M.P. 1968. Transmissores do Trypanosoma cruzi: os triatomíneos. In CANÇADO, J.R. Doença de Chagas. Belo Horizonte. Imp. Of. do Estado, p. 189-224.

BATISTA, S.M. 1973. Teste de hemaglutinação com diferentes antígenos no diagnóstico da doença de Chagas. Tese. Departamento de Zoologia e Parasitologia, Instituto de Ciências Biológicas, UFMG. Belo Horizonte, MG.

DEANE, L.M. 1973. Informação pessoal.

DIAS, E. 1958. Epidemiologia e profilaxia da doença de Chagas. Rev. Goiana Med. 4:303-317.

DIAS, J.C.P. \& Garcia, A.L. 1975. Vigilância epidemiológica contra doença de Chagas com participação da comunidade. (No prelo).

FREITAS, J.L.P. 1968. Profilaxia da moléstia de Chagas. In CANÇADO, J.R. Doença de Chagas. Belo Horizonte, Imp. Of. do Estado, p.541-559.

FUNDAÇÃO JOÃO PINHEIRO. 1975. Pré-diagnóstico da região mineira da SUDENE. Belo Horizonte, MG.

FUNDAÇÃO SESP. 1968. Secretaria de Estado da Saúde de Minas Gerais. Diagnóstico de saúde na área mineira da SUDENE. Belo Horizonte. (Mimeografado).

IPPEDASAR. 1972. Secretaria de Estado da Saúde de Minas Gerais. Sistema regional de saúde no Norte de Minas Gerais. Belo Horizonte.

MARTINS, A.V. 1968. Epidemiologia da doença de Chagas. In CANÇADO, J.R. Doença de Chagas. Belo Horizonte, Imp. Of. do Estado, p. 225-237.

MAURICIO, J.V. 1959. A Doença de Chagas no Norte de Minas Gerais. Dados apresentados no Congresso Internacional de Doença de Chagas. Rio de Janeiro, Brasil.

SALGADO, A.A. \& PELLEGRINO, J. 1957. Realização de inquérito sorológico em zona rural: processo prático para a obtençāo de amostras de sangue. Rev. Bras. Malariol. Doen. Trop. 12:359-360.

SALGADO, A.A. \& PELLEGRINO, J. 1968. Distribuição geográfica: inquérito sorológico. In CANÇADO, J.R. Doença de Chagas. Belo Horizonte, Imp. Of. do Estado, p. 143162.

SUCAM. Setor de Minas Gerais. 1975. Arquivos. 